\title{
Are We Sure that Adjuvant Chemotherapy is the Best Approach for Resectable Pancreatic Cancer? Are We in the Era of Neoadjuvant Treatment? A Review of Current Literature
}

\author{
Ester Oneda and Alberto Zaniboni * \\ Department of Clinical Oncology, Fondazione Poliambulanza, 25124 Brescia, Italy; ester.oneda@poliambulanza.it \\ * Correspondence: alberto.zaniboni@poliambulanza.it
}

Received: 17 September 2019; Accepted: 7 November 2019; Published: 8 November 2019

\begin{abstract}
The outcome of pancreatic cancer is poor, with a 9\% 5-year survival rate. Current treatment recommendations in the $10 \%-20 \%$ of patients who present with resectable disease support upfront resection followed by adjuvant therapy. Until now, only early complete surgical (R0) resection and adjuvant chemotherapy (AC) with either FOLFIRINOX (5-fluorouracil, leucovorin, irinotecan, and oxaliplatin) or nab-paclitaxel plus gemcitabine have been shown to prolong the survival. However, up to $30 \%$ of patients do not receive adjuvant therapy because of the development of early recurrence, postoperative complications, comorbidities, and reduced performance status. The aims of neoadjuvant chemotherapy (NAC) are to identify rapidly progressing patients to avoid futile surgery, eliminate micrometastases, increase the feasibility of $\mathrm{R} 0$ resection, and ensure the completion of multimodal treatment. Neoadjuvant treatments are effective, but there is no consensus on their use in resectable pancreatic cancer (RPC) because of its lack of a survival benefit over adjuvant therapy. In this review, we analyze the advantages and disadvantages of the two therapeutic approaches in RPC. We need studies that compare the two approaches and can identify the appropriate sequence of adjuvant therapy after neoadjuvant treatment and surgery.
\end{abstract}

Keywords: pancreatic cancer; adjuvant chemotherapy; neoadjuvant chemotherapy

\section{Introduction}

Pancreatic cancer (PC) is one of the most deadly cancers in developed countries. The incidence of PC in western Europe is 7.3 per 100,000 individuals, and the mortality rate is 6.8 per 100,000 individuals [1]. PC represents the fourth leading cause of death related to cancer after lung, colorectal, and prostate cancers in men and after breast, colorectal and lung cancers in women [2,3], with a 5-year survival rate of $9 \%$ when considering all stages [4,5]. Pancreatic cancer mortality has been increasing in both genders in recent decades [1]; this increase could be related to the gain of therapeutic advantages in other types of cancers compared with PC and to the growing prevalence of pancreatic cancer [6].

For the $10 \%-20 \%$ of patients with resectable disease, clinical data support upfront resection and adjuvant therapy. In borderline resectable pancreatic cancer (BRPC), surgical resection could follow induction chemotherapy to reduce tumor size and control potential micrometastatic disease $[7,8]$. Although surgical techniques have advanced and adjuvant treatment has been standardized, survival rates remain low; early total surgical (R0) resection with lymph node dissection and removal of the extrapancreatic nerve plexus and celiac axis $[9,10]$ are the key factors influencing survival. Adjuvant therapy prolonged survival after surgery and has become the standard treatment for resectable pancreatic cancer (RPC). Adjuvant chemotherapy (AC) with 5-fluorouracil plus folinic acid or gemcitabine has already been shown to prolong the 5 -year survival by approximately $16 \%-21 \%$ [11-13], 
and the new combination regimens have another promising advantage. However, in clinical practice many patients develop early relapse despite complete surgical resection [14,15]. Approximately $30 \%$ of patients fail to receive adjuvant therapy because of postoperative complications, early metastases, reduced performance status, and comorbidities [16].

This lack of efficacy in patients allowed for the development of neoadjuvant chemotherapy (NAC) with a focus on identifying aggressive tumors in order to avoid inappropriate surgery, eliminate micrometastases, increase complete resectability (at the R0 stage), reduce tumor seeding risk at the time of surgery and complete multimodal treatments $[7,8]$. There are data suggesting that most PCs are likely to exhibit micrometastases even when only a small primary tumor is detectable by clinical imaging, leading to early relapse and death after surgery. Effective chemotherapy could treat these micrometastases and prevent early post-surgery recurrence [17]. Possible disadvantages of NAC are the potential complications associated with biliary stents or the necessity for biliary decompression during treatment and the delay of surgery. These events could lead to disease progression (in approximately $20 \%$ of PCs [18,19]), a potential increase in the occurrence of postoperative complications [20] and only a few benefits in overall survival (OS) and disease-free survival (DFS), as has been observed in several meta-analyses $[21,22]$. Despite this, NAC is widely accepted for the management of locally advanced (LA) and borderline resectable (BR) cases [7,8,23], but no evidence exists on the benefit in RPC.

Neither randomized trials nor reviews identify a survival advantage of neoadjuvant treatment because they include different patient types (BR, LA, and RPC), the number of patients is often insufficient, the surgery was performed in a low-volume surgery hospital, resectability criteria and the criteria to proceed after neoadjuvant treatment lack consensus, and the mOS is often underestimated because many patients were not eligible to receive curative resection. Furthermore, it is not clear whether any adjuvant regimen should be delivered after neoadjuvant treatment and surgery and which regimen should be used.

\section{Neodjuvant Treatment-The Data}

Ideally, neoadjuvant chemotherapy could be offered to a greater number of patients than adjuvant chemotherapy because of its early administration in patients with a better performance status than patients who have undergone resection, which allows them to have good tolerance to multi-agent regimens and a higher negative-margin resection rate than that seen after upfront surgery. Randomized trials have tried to show which is the most suitable neoadjuvant treatment.

Tajima et al. [20] treated 52 BR patients with neoadjuvant therapy with GEM-based regimens (GEM monotherapy, GEM plus S-1 therapy, or nabPTX plus GEM therapy) for two cycles, and then surgery was performed. In the control group, 34 patients underwent upfront surgery. Both arms received adjuvant gemcitabine after resection. Partial response (PR) was achieved in five of the 52 NAC group patients, stable disease (SD) was achieved in 45 patients $(86.5 \%)$, and progressive disease (PD) occurred in 2 patients (3.9\%); however, on computed tomography (CT) scan, no significant tumor volumetric reduction was observed after NAC, and only the CA 19.9 mean value significantly decreased. All tumor samples showed histopathological cell tumor injury, although pathological complete response (CR) was not seen in any patient. Unfortunately, the 5-year OS rates in the NAC group compared with the control group were not increased. A total of $40.7 \%$ of patients relapsed within one year after surgery. The negative predictors of response were the CA 19.9 value, tumor stage, number of lymph node metastases, and rates of nerve and plexus invasion [20].

The phase II/III trial JSAP05 from Japan showed that in BR and resectable cancer patients, there was a resection rate of $93 \%$ and an mOS of 36.72 months with neoadjuvant treatment with the combination of gemcitabine plus $\mathrm{S} 1$, an orally active fluoropyrimidine, followed by surgery and adjuvant treatment with S1, as compared to a resection rate of $82 \%$ and an mOS of 26.65 months seen with upfront surgery (US) plus adjuvant treatment with S1 [24]. Furthermore, neoadjuvant treatment improved the 2-year OS rate from $52.5 \%$ to $63.7 \%$. The benefit from neoadjuvant treatment was observed in most subgroups in the forest plot analysis. The time to surgery and surgery-related morbidity was not modified 
with neoadjuvant gemcitabine plus S1 treatment. Additionally, pN1 occurrence was significantly lower in the NAC arm than in the US arm (59.6\% vs. 81.5\%) [24]. For a different metabolism of the drug, the Western population showed higher toxicity with S1 than Asians, and studies are needed to evaluate the efficacy of S1 in that population. In addition, other studies have been carried out in Western population; Janssen et al. [25] analyzed the effects of neoadjuvant FOLFIRINOX (5-fluorouracil, leucovorin, irinotecan, and oxaliplatin) in patients with BRPC and LAPC and found a good resection rate $(67.8 \%$; 95\% CI: 60.1-74.6), while the R0 resection rate was $83.9 \%$ (95\% CI: $76.8-89.1)$. The median OS was 22.2 months (95\% CI: 18.8-25.6), and the median PFS was 18.0 months (95\% CI: 14.5-21.5) [25]. Because FOLFIRINOX was more effective than gemcitabine alone in patients with advanced pancreatic cancer [26], it is expected that it could improve OS in a neoadjuvant setting. Recently, Michelakos et al. published data from Massachusetts General Hospital showing a median OS of 37.7 months after neoadjuvant FOLFIRINOX [27].

PREOPANC-1, a phase III randomized trial comparing neoadjuvant chemoradiotherapy (NACRT) followed by surgery, found a better DFS with NACRT than that seen in patients who had upfront surgery (US). Furthermore, the 2-year survival rate was higher for NARCT than for US ( $42 \%$ vs. $30 \%$ ). The study enrolled 246 patients with BRPC, who were randomly assigned to receive US or chemoradiotherapy (15 fractions of 2.4 gray (Gy) combined with weekly gemcitabine) followed by surgery. Both groups also received AC with gemcitabine. The median overall survival was 17.1 months with NARCT compared to 13.7 months with US. The time until cancer recurrence was longer with preoperative therapy ( 9.9 vs. 7.9 months) than without preoperative therapy. Among the resected patients, the difference in median survival was even greater: 42.1 months with preoperative treatment vs. 16.8 months with US. The resection rate was $72 \%$ in the US group and $62 \%$ in the chemoradiotherapy group. Among the resected patients, the tumor was microscopically completely removed in the $63 \%$ of patients who received NACRT and in $31 \%$ of patients who receive US [28]. In addition, patients treated with NACRT had less surgical site infections (SSIs), a higher curative resection rate, and an earlier stage of disease than patients who were not treated. On the other hand, an important increase of the risk of mortality is a low muscle mass at diagnosis, associated with loss of lean tissue during chemotherapy. Sarcopenia was prevalent in half of patients at the time of diagnosis with PC. NACRT can induce a low prognostic nutritional index (PNI), that can be associated with the poor patient condition and low tolerability of adjuvant chemotherapy [29-31]. Recent guidelines recommended assessing the patient's nutritional status from the start of treatment and monitoring it [30]. With these considerations, NAC should be avoided in sarcopenic patients to give them a chance at resection. Future clinical trials comparing neoadjuvant chemoradiation with neoadjuvant chemotherapy are needed to confirm these results.

The phase II SWOG S1505 (ClinicalTrials.gov, NCT02562716) trial is investigating the safety and effectiveness of ABRAXANE in combination with gemcitabine in neoadjuvant environments. Preliminary data show that $(42 ; 29 \%)$ patients were ineligible for the study because of venous involvement $\geq 180^{\circ}$, arterial involvement, or distant disease at the time of diagnosis [32,33]. Of the eligible patients, $73 \%$ underwent resection. We do not yet have data on the number of patients completing the treatment and on DFS and OS.

ESPAC-5: A multi-centre, prospective, randomized phase II trial, is recruiting patients to compare neoadjuvant therapy (GemCap or FOLFIRINOX) or chemoradiotherapy to immediate surgical exploration in patients with borderline resectable pancreatic cancer. All resected patients will also receive adjuvant chemotherapy with either gemcitabine or 5-fluorouracil for six cycles according to physician choice [34]. As can be seen in Tables 1 and 2 (with small retrospective studies), it is not possible to make a direct comparison between the studies and reviews listed. 
Table 1. Analysis of survival and R0 status with neoadjuvant treatments according to updated studies and reviews.

\begin{tabular}{|c|c|c|c|c|c|c|c|c|c|c|}
\hline \multirow{3}{*}{$\begin{array}{c}\text { Type of pz }(\boldsymbol{n}) \\
\text { Regimen }\end{array}$} & \multicolumn{2}{|c|}{ JSAP-05 [24] } & \multirow{2}{*}{\multicolumn{2}{|c|}{$\begin{array}{c}\text { Tajima [20] } \\
\text { RPC }\end{array}$}} & \multirow{2}{*}{\multicolumn{2}{|c|}{$\begin{array}{c}\text { Michelakos [27] } \\
\text { BRCP (69), LAPC (71) }\end{array}$}} & \multirow{2}{*}{\multicolumn{2}{|c|}{$\begin{array}{c}\text { PREOPANC 1 [28] } \\
\text { BRCP (246) }\end{array}$}} & \multicolumn{2}{|c|}{ Jassen [25] } \\
\hline & RPC, BRPC (182) & RPC, BRPC (180) & & & & & & & BRCP (283) & LAPC (315) \\
\hline & $\begin{array}{l}\text { Gem }+ \text { S1 + surgery } \\
+ \text { S1 (adj) }\end{array}$ & Surgery + S1 (adj) & $\begin{array}{c}\text { Gem regimen }(\text { gem+S1/gem/nab-P+gem) } \\
+ \text { surgery + gem }(\text { adj })\end{array}$ & $\begin{array}{l}\text { Surgery }+ \\
\text { gem (adj) }\end{array}$ & $\begin{array}{l}\text { FOLFIRINOX } \\
+ \text { surgery }\end{array}$ & Surgery & $\begin{array}{l}\text { NACRT + surgery + } \\
\text { gem (adj) }\end{array}$ & $\begin{array}{l}\text { Surgery }+ \\
\text { gem (adj) }\end{array}$ & $\begin{array}{l}\text { FOLFIRINOX } \\
+ \text { surgery }\end{array}$ & $\begin{array}{l}\text { FOLFIRINOX } \\
\text { + surgery }\end{array}$ \\
\hline mOS (months) & 36.72 & 26.65 & 41.6 & 23.3 & 37.7 & 25.1 & 17.1 & 13.7 & 22.2 & 24.2 \\
\hline $\mathrm{HR}$ & & & & & & & 0.74 & & & \\
\hline mDFS (months) & & & & & 29.1 & 13.7 & 9.9 & 7.9 & 18 & \\
\hline HR & & & & & & & 0.23 & & & \\
\hline R0 (\%) & & & 80.8 & 79.04 & 78 (R tot) & & 63 & 31 & 83.9 & 27 \\
\hline
\end{tabular}

BRPC = borderline resectable pancreatic cancer; LAPC = locally advance pancreatic cancer; RPC = resectable pancreatic cancer; Gem = gemcitabine; nab-P = nab-paclitaxel; FOLFIRINOX

= combination chemotherapy with fluorouracil, leucovorin, irinotecan, and oxaliplatin; NACRT= neoadjuvant chemoradiotherapy with weekly gemcitabine.

Table 2. Summary of prospective and retrospective trials to assess the efficacy of neoadjuvant treatments (not cited in the text).

\begin{tabular}{|c|c|c|c|c|c|c|c|}
\hline Study & Type of pz (n) & Regimen $(n)$ & mOS (Month) & PD $(n)$ & PR $(n)$ & $\mathrm{SD}(n)$ & Resection $(n)$ \\
\hline Kunzmann V et al. [35] & 8 LAPC & NabP + gemFOLFIRINOX (adj) & & & 5 & 3 & 3 \\
\hline Sueyoshi H et al. [36] & 14 LAPC & W-nabP +gem + RT & & 4 & 2 & 6 & \\
\hline Reni M et al. [37] & 24 LAPC & $\mathrm{NabP}+$ cis/cape/gem (PAXG) & & & 16 & 8 & $6(3 \mathrm{R} 0)$ \\
\hline Reni M et al. [38] & 223 LAPC & NabP + gem (28) or others gem regimens (195) & & 11 & 106 & 103 & $61(38 \mathrm{R} 0)$ \\
\hline LAPACT [39] & 107 LAPC & $\mathrm{NabP}+$ gem & & 5 & 35 & 83 & 16 (7 R0) \\
\hline PACT-19 [40] & 54 (BRPC and LAPC) & $\mathrm{NabP}+$ gem (28) or nabP + cis/cape/gem (PAXG) (26) & & & & & 17 \\
\hline Khushman M et al. [41] & 51 LAPC & FOLFIRINOX + CRT & & & & & 10 R0 \\
\hline Nitsche U et al. [42] & 14 LAPC & FOLFIRINOX & & 1 & 6 & 6 & 4 \\
\hline Hackert T et al. [43] & 575 LAPC & FOLFIRINOX (125) or gem regimens (322) or others regimens (128) & 16 & & & & $76(31 \mathrm{R} 0)$ \\
\hline Pfeiffer P et al. [44] & 59 (BRPC and LAPC) & $\begin{array}{l}\text { FOLFIRINOX }+ \text { CRT } \\
\end{array}$ & & & & & 16 \\
\hline Suker M et al. [45] & 315 & FOLFIRINOX & & & & & $81(63 \mathrm{R} 0)$ \\
\hline Lloyd S et al. [46] & 115 (BRPC and LAPC) & CRT or CT or CCRT & $12.5,13.9,21.5$ & & & & $53(2 \mathrm{R} 0)$ \\
\hline Casadei R et al. [47] & 18 LAPC & CRT & 22.4 & 5 & 4 & 18 & 7 R0 \\
\hline Fujii et al. [48] & $21 \mathrm{BRPC}$ & CRT & 29.1 & & & & 18 \\
\hline Fujii et al. [49] & $504 \mathrm{BRPC}$ and RPC & CRT & 28.6 & & & & \\
\hline Satoi $\mathrm{S}$ at al. [50] & 67(BRPC and LAPC) & $\mathrm{CRT}+\mathrm{S} 1$ (35) or gem + S1 (32) & 22 & & & & 31,25 \\
\hline Murakami Y et al. [51] & $52 \mathrm{RPC}$ & $\mathrm{Gem}+\mathrm{S} 1$ & 27.1 & & & & 38 \\
\hline
\end{tabular}

$\mathrm{BRPC}=$ borderline resectable pancreatic cancer; LAPC $=$ locally advance pancreatic cancer; RPC $=$ resectable pancreatic cancer; CCRT $=$ chemotherapy followed by chemoradiation therapy; $\mathrm{CRT}=$ chemoradiotherapy; $\mathrm{CT}=$ chemotherapy; $\mathrm{Gem}=$ gemcitabine; $\mathrm{nabP}=$ nab-paclitaxel mFOLFIRINOX = combination chemotherapy with fluorouracil, leucovorin, irinotecan, and oxaliplatin; Cis = cisplatin; Cape = capecitabine; $\mathrm{PD}=$ progressive disease; $\mathrm{PR}=$ partial response; $\mathrm{SD}=$ stable disease. 


\section{Adjuvant Treatment-The Data}

Up to a 30\% 5-year survival rate can be achieved if adjuvant chemotherapy is delivered after surgical resection [52]. Since CONKO-001 demonstrated the efficacy of gemcitabine (GEM) as a postoperative adjuvant treatment in $2007[13,53]$ with a 5-year survival rate of $20.7 \%$, it has become the standard of care.

The 5-year survival rate was estimated in the ESPAC-1, ESPAC-3, and ESPAC-4 trials (fluorouracil vs. control, gemcitabine vs. fluorouracil, gemcitabine plus capecitabine vs. gemcitabine); it was $21 \%$ vs. $8 \%, 17.5 \%$ vs. $15.9 \%$, and $28.8 \%$ vs. $16.3 \%$ respectively [11,52,54]. ESPAC-3 did not show a survival benefit of adjuvant gemcitabine than 5-fluoruracil and folinic acid [54]. In ESPAC-4 [52], the combination of gemcitabine and capecitabine (an orally active prodrug of 5-fluoruracil) performed better than gemcitabine with an increase in progression-free survival and overall survival $28 \mathrm{vs}$. 25.5 months (HR $0.82(95 \%$ CI 0.68-0.98), $p=0.032)$. One factor correlates to survival is the resection margins status, the median overall survival was 23.7 vs. 23 months for patients who had positive resection margins (R1 status) and 39.5 vs. 27.9 months in who had negative resection margins (R0 status). Other factors that emerged as related to survival were smoking, preoperative, and postoperative CA19.9 serum levels, preoperative C-reactive protein concentrations, tumor grade, lymph nodes status, maximum tumor size, tumor stage, venous resection, and local invasion.

The JASPAC-1 trial also showed superior survival with S1 compared to gemcitabine. The 5-year OS was $44.1 \%$ in the S-1 group and $24.4 \%$ in the gemcitabine group. Tests of S1 are required to assess its efficacy and the safety in Western populations [55].

The recent trial PRODIGE showed that combination chemotherapy with fluorouracil, leucovorin, irinotecan, and oxaliplatin (FOLFIRINOX), previously tested in the metastatic setting [26], lead to longer disease-free survival, overall survival, metastasis-free survival, and cancer-specific survival than gemcitabine therapy [56]. The median overall survival was 54.4 months in the modified-FOLFIRINOX group and 35 months in the gemcitabine group. The 3-years OS rate was 63.4\% in the modified-FOLFIRINOX group and $48.6 \%$ in the gemcitabine group. As expected, the modified FOLFIRINOX regimen was more toxic than gemcitabine; in particular, grade 3 or 4 neutropenia and diarrhea occurred in $75.9 \%$ of the patients in the modified-FOLFIRINOX group and in $52.9 \%$ of patients in the gemcitabine group [56].

A recent report from the phase III APACT study showed that the use of adjuvant treatment with nab-paclitaxel (ABRAXANE) in combination with gemcitabine did not improve disease-free survival compared to the use of gemcitabine alone (mDFS 19.4 months vs. 18.8 months), while overall survival was improved (mOS 40.5 months vs. 36.2 months) [57]. The results of these studies are resumed in Table 3.

Valle et al. reported that an independent prognostic factor after PC resection was the completion of planned cycles of adjuvant chemotherapy, rather than its early administration [37]. In many trials, with highly selected patients who have completely recovered from surgery, the completion rate of chemotherapy ranges from 54 to $79 \%$ [26,52]. A.M. Altman et al. [58] studied the rate of completion of $\mathrm{AC}$ and the factors associated with completion. They collected 2440 patients who underwent upfront surgery, $65 \%$ of the patients received no AC, $28 \%$ received incomplete AC, and only $7 \%$ completed six cycle of AC [58]. T. Akahori et al. [59] analyzed 135 patients: 90 patients completed planned adjuvant chemotherapy, while 45 patients failed to complete adjuvant chemotherapy. A total of $14.8 \%$ of patients experience recurrence during the treatment, and $18.5 \%$ of the patients ceased treatment before completion because of poor performance status. 
Table 3. Survival with selected adjuvant treatment in resected pancreatic cancer.

\begin{tabular}{|c|c|c|c|c|c|c|c|c|c|c|c|c|c|c|}
\hline \multirow[b]{2}{*}{ Regimen } & \multicolumn{2}{|c|}{ CONKO-001 } & \multicolumn{2}{|l|}{ ESPAC-1 } & \multicolumn{2}{|l|}{ ESPAC-3v } & \multicolumn{2}{|c|}{ ESPAC-4 } & \multicolumn{2}{|c|}{ JASPAC-1 } & \multicolumn{2}{|c|}{ PRODIGE 24} & \multicolumn{2}{|l|}{ APACT } \\
\hline & Gem & Obs & $5 \mathrm{FU}+$ Folinic Acid & Obs & $5 \mathrm{FU}+$ Folinic Acid & Gem & Gem + Cape & Gem & S1 & Gem & mFOLFIRINOX & Gem & PacliT + Gem & Gem \\
\hline mOS (months) & 22.8 & 20.2 & 20.1 & 15.5 & 23.1 & 23.6 & 28 & 25.5 & 46.5 & 25.5 & 54.4 & 35 & 40.5 & 36.2 \\
\hline HR $(95 \%$ CI $)$ & \multicolumn{2}{|c|}{0.76} & \multirow[t]{2}{*}{0.66} & & \multicolumn{2}{|l|}{0.94} & \multicolumn{2}{|l|}{0.82} & \multicolumn{2}{|c|}{0.57} & \multicolumn{2}{|l|}{0.64} & \multicolumn{2}{|l|}{0.82} \\
\hline mDFS (months) & 13.4 & 6.7 & & & 14.1 & 14.3 & 13.9 & 13.1 & 22.9 & 11.3 & 21.6 & 12.8 & 19.4 & 18.8 \\
\hline HR $(95 \%$ CI) & \multicolumn{2}{|c|}{0.55} & & & \multicolumn{2}{|l|}{0.96} & \multicolumn{2}{|l|}{0.86} & \multicolumn{2}{|c|}{0.60} & \multicolumn{2}{|l|}{0.58} & \multicolumn{2}{|l|}{0.88} \\
\hline 5 yrs OS (\%) & 20.7 & 10.4 & 21.1 & 8 & 15.9 & 17.5 & 28.8 & 16.3 & 44.1 & 24.4 & 63.4 (3 yrs OS) & $\begin{array}{c}48.6 \\
(3 \\
\text { yrs } \\
\text { OS) }\end{array}$ & & \\
\hline
\end{tabular}

Obs = observation; Gem = gemcitabine; 5 FU = 5-fluorouracil; Cape = capecitabine; mFOLFIRINOX = combination chemotherapy with fluorouracil, leucovorin, irinotecan, and oxaliplatin. 
In conclusion, the factors associated with the completion of chemotherapy after resection are performance status and disease-related comorbidities at the time of diagnosis [60-62] and surgical morbidity; half of the patients present with a major postoperative complication $[61,63,64]$. Indeed, a serum CA 19.9 level $>85 \mathrm{U} / \mathrm{mL}$ within 6 months after upfront surgery was an independent risk factor for recurrence $[20,29]$. Predictors of poor prognosis associated with failure to complete adjuvant chemotherapy included early recurrence, high serum CA 19.9, presence of lymph node metastasis, and positive surgical margins $[65,66]$, low preoperative prognostic nutritional index, intraoperative blood transfusion, infection of the surgical site, and advanced tumor stage. Studies are needed to find the most effective and least toxic chemotherapy regimen to overcome these problems.

\section{Discussion}

The only way to cure PC is R0 resection, but R1 resections are reported in many cases [67], and even after undergoing curative resection, the local recurrence rate is $50 \%-80 \%$ and the probability of developing distant metastases is $25 \%-50 \%$ [68]. Multiple trials have shown a survival benefit for adjuvant chemotherapy after resection of PC, but not all RPC patients are able to complete the planned AC because of early recurrence during therapy (approximately 34\% [63,69]) or to poor postoperative patient condition. Neoadjuvant treatment could improve the R0 resection rate, reduce the risk of early metastasis, and consequently increase overall survival. Short induction chemotherapy followed by consolidation therapy after resection has been shown to be successful in other solid gastrointestinal tumors, but it has not been observed in PC. The median OS seems to be inferior with neoadjuvant treatment compared with adjuvant treatment in many metanalyses; the mOS with adjuvant FOLFIRINOX chemotherapy in the PRODIGE24 trial [56] was 54.4 months while in the neoadjuvant setting, it is approximately 24 months [25]. The patients in the adjuvant and neoadjuvant trials were very different and cannot be compared directly. In fact, for adjuvant trials, the patients are required to meet certain criteria: complete macroscopic resection, complete recovery after surgery, and level of CA 19.9 under stabilized values; many patients are not included because of surgical complications and metastases that were found during surgery. Only one-third of patients receive adjuvant therapy.

No study has been designed to compare the survival in RPC with neoadjuvant vs. adjuvant chemotherapy. The still unanswered question is whether NAT or upfront surgery and adjuvant therapy are the appropriate strategies in resectable pancreatic cancer. Until now, the published studies included a mixture of patients with resectable or borderline resectable or even unresectable tumors, so we cannot determine clear conclusions, we urgently need clarification.

Nowadays several trials are recruiting resectable pancreatic cancer patients worldwide and are comparing the systemic neoadjuvant and adjuvant treatments. In Germany, the NEONAX trial is comparing 2 cycles of nab-paclitaxel $\left(125 \mathrm{mg} / \mathrm{m}^{2}\right) / \mathrm{gemcitabine}\left(1000 \mathrm{mg} / \mathrm{m}^{2}\right.$, on d1, 8 and 15 of a 28-day cycle) followed by surgery and 4 cycles of nab-paclitaxel/gemcitabine therapy, with surgery followed by 6 cycles of nab-paclitaxel/gemcitabine [70]. The rational of the use of two cycles of NAT take into consideration the lower tolerability with increasing therapy cycles and the good effectiveness (tumor regression in 30\% of patients in a phase I trial) [71]. Furthermore, in a phase I/II trial, a reduction in the absorption of FDG was observed after 6 weeks of treatment with nab-paclitaxel/gemcitabine, suggesting that 2 cycles of this regimen are sufficient [72], and a further delay of surgery could reduce patient compliance. Other trials are recruiting patients: the NEOPAC study (NCT01314027, comparing neoadjuvant gemcitabine and oxaliplatin regimens with upfront surgery, all followed by adjuvant gemcitabine) [73]; the NEPAFOX trial (NCT02172976, comparing neoadjuvant chemotherapy with FOLFIRINOX, US follow by adjuvant FOLFIRINOX, and US follow by adjuvant gemcitabine) [74]; NorPACT-1 trial (NCT02919787, comparing neoadjuvant FOLFIRINOX with upfront surgery; both groups receive adjuvant chemotherapy gemcitabine and capecitabine) [75]; the PANACHE01-PRODIGE48 trial (NCT02959879, comparing two regimens of neoadjuvant chemotherapy: 4 cycles of mFOLFIRINOX or 4 cycles of FOLFOX; both are 
followed by surgery and adjuvant therapy) [76]; and the PREOPANC-2 trial (NTR7292, comparing neoadjuvant chemotherapy with FOLFIRINOX or gemcitabine plus capecitabine, with neoadjuvant gemcitabine-based CRT with upfront surgery). We are waiting for the results (studies are resumed in Table 4).

Table 4. Ongoing trials.

\begin{tabular}{|c|c|c|c|}
\hline & Arm A & Arm B & Arm C \\
\hline NEONAX & $\begin{array}{l}\text { Neoadjuvant nab-P+gem }+ \text { surgery }+ \\
\text { adjuvant nab-P }+ \text { Gem }\end{array}$ & Surgery + adjuvant nab-P + Gem & \\
\hline NEOPAC & $\begin{array}{c}\text { Neoadjuvant gem }+ \text { surgery+ } \\
\text { adjuvant gem }\end{array}$ & $\begin{array}{c}\text { Neoadjuvant Oxaliplatin }+ \text { surgery }+ \\
\text { adjuvant gem }\end{array}$ & Surgery + adjuvant gem \\
\hline NEPAFOX & Neoadjuvant mFOLFIRINOX & Adjuvant mFOLFIRINOX & Adjuvant gem \\
\hline NorPACT-1 & $\begin{array}{c}\text { Neoadjuvant mFOLFIRINOX }+ \\
\text { surgery + adjuvant gem plus cape }\end{array}$ & $\begin{array}{l}\text { Surgery }+ \text { adjuvant gemcitabine plus } \\
\text { capecitabine }\end{array}$ & \\
\hline PREOPANC-2 & Neoadjuvant mFOLFIRINOX & $\begin{array}{l}\text { Neoadjuvant gem-based } \\
\text { chemoradiotherapy }\end{array}$ & \\
\hline ESPAC-5 & $\begin{array}{l}\text { Neoadjuvant mFOLFIRINOX or Gem } \\
\text { plus cape }\end{array}$ & Neoadjuvant chemoradiotherapy & Up front surgery \\
\hline
\end{tabular}

Gem = gemcitabine; nab-P = nab-paclitaxel; mFOLFIRINOX = combination chemotherapy with fluorouracil, leucovorin, irinotecan, and oxaliplatin; FOLFOX = combination chemotherapy with fluorouracil, leucovorin and oxaliplatin.

Subsequently, the problem of which treatment to propose after relapse of the disease will arise. Gbolahan et al. [77] observed 10-month median post-relapse OS (mOS) in patients with resected pancreatic cancer who had received combination therapy or monotherapy after relapse and 3-month mOS in patients undergoing best supportive care (BSC). In particular, the 14-month OS improvement was much more evident with a standard combination therapy regimen than with a single agent or non-standard combination chemotherapy [77]. There is a lack of studies on the use of chemotherapy in patients with resected PC who relapsed after an initial curative therapy with both neoadjuvant and adjuvant treatment, and it is not clear to what extent the first therapy may influence the efficacy and tolerability of the subsequent chemotherapy.

\section{Conclusions}

The outcome of pancreatic cancer remains poor, but survival is slowly increasing with a reported median OS of 54.4 months with adjuvant chemotherapy with FOLFIRINOX after surgery [56] while, until now, there has been no evidence of a survival benefit with neoadjuvant treatment in resectable pancreatic cancer patients. In order to improve the survival, the sequence of neoadjuvant and adjuvant treatment need to be explored in clinical trials. Clinicians are awaiting guidance on which therapeutic strategy is the best. The patients and regimens used in recent studies are very different and cannot be compared directly; we are awaiting the results of ongoing trials, which will hopefully clarify the current state of the field.

Conflicts of Interest: Authors declared no potential conflict of interest.

\section{References}

1. Ilic, M.; Ilic, I. Epidemiology of pancreatic cancer. World J. Gastroenterol. 2016, 22, 9694-9705. [CrossRef]

2. Ducreux, M.; Cuhna, A.S.; Caramella, C.; Hollebecque, A.; Burtin, P.; Goéré, D.; Seufferlein, T.; Haustermans, K.; Van Laethem, J.L.; Conroy, T. Cancer of the pancreas: ESMO Clinical Practice Guidelines for diagnosis, treatment and follow-up. Ann. Oncol. 2015, 26, 56-68. [CrossRef] [PubMed]

3. Malvezzi, M.; Carioli, G.; Bertuccio, P.; Boffetta, P.; Levi, F.; La Vecchia, C.; Negri, E. European cancer mortality predictions for the year 2017, with focus on lung cancer. Ann. Oncol. 2017, 28, 1117-1123. [CrossRef] [PubMed] 
4. Bray, F.; Ferlay, J.; Soerjomataram, I.; Siegel, R.L.; Torre, L.A.; Jemal, A. Global cancer statistics 2018: GLOBOCAN estimates of incidence and mortality worldwide for 36 cancers in 185 countries. CA Cancer J. Clin. 2018, 68, 394-424. [CrossRef] [PubMed]

5. Neoptolemos, J.P.; Kleeff, J.; Michl, P.; Costello, E.; Greenhalf, W.; Palmer, D.H. Therapeutic developments in pancreatic cancer: Current and future perspectives. Nat. Rev. Gastroenterol. Hepatol. 2018, 15, 333-348. [CrossRef] [PubMed]

6. Seufferlein, T.; Hammelb, P.; Delpero, J.R.; Macarulla, T.; Pfeiffer, P.; Prager, G.W.; Reni, M.; Falconi, M.; Philip, P.A.; Van Cutsem, E. Optimizing the management of locally advanced pancreatic cancer with a focus on induction chemotherapy: Expert opinion based on a review of current evidence. Cancer Treat. Rev. 2019, 77, 1-10. [CrossRef] [PubMed]

7. Asare, E.A.; Evans, D.B.; Erickson, B.A.; Aburajab, M.; Tolat, P.; Tsai, S. Neoadjuvant treatment sequencing adds value to the care of patients with operable pancreatic cancer. J. Surg. Oncol. 2016, 114, 291-295. [CrossRef] [PubMed]

8. Lee, J.; Ahn, S.; Paik, K.H.; Kim, H.W.; Kang, J.; Kim, J.; Hwang, J.H. Clinical impact of neoadjuvant treatment in resectable pancreatic cancer: A systematic review and meta-analysis protocol. BMJ Open 2016, 6, 1-9. [CrossRef]

9. Verbeke, C.S.; Menon, K.V. Redefining resection margin status in pancreatic cancer. HPB 2009, 11, $282-289$. [CrossRef]

10. Kitagawa, H.; Tajima, H.; Nakagawara, H.; Isamu, M.; Miyashita, T.; Terakawa, H.; Nakanuma, S.; Hayashi, H.; Takamura, H.; Ohta, T. A modification of radical antegrade modular pancreato-splenectomy for adenocarcinoma of the left pancreas: Significance of en bloc resection including the anterior renal fascia. World J. Surg. 2014, 38, 2448-2454. [CrossRef]

11. Neoptolemos, J.P. ESPAC-1: A European, randomized controlled study of adjuvant chemoradiation and chemotherapy in resectable pancreatic cancer. Lancet 2001, 358, 1576-1585. [CrossRef]

12. Neoptolemos, J.P.; Stocken, D.D.; Friess, H.; Bassi, C.; Dunn, J.A.; Hickey, H.; Beger, H.; Fernandez-Cruz, L.; Dervenis, C.; Lacaine, F.; et al. A randomized trial of chemoradiotherapy and chemotherapy after resection of pancreatic cancer. N. Engl. J. Med. 2004, 350, 1200-1210. [CrossRef] [PubMed]

13. Oettle, H.; Neuhaus, P.; Hochhaus, A.; Hartmann, J.T.; Gellert, K.; Ridwelski, K.; Niedergethmann, M.; Zülke, C.; Fahlke, J.; Arning, M.B.; et al. Adjuvant chemotherapy with gemcitabine and long-term outcomes among patients with resected pancreatic cancer: The CONKO-001 randomized trial. JAMA 2013, 310, 1473-1481. [CrossRef] [PubMed]

14. Winter, J.M.; Brennan, M.F.; Tang, L.H.; D’Angelica, M.I.; DeMatteo, R.P.; Fong, Y.; Allen, P.J. Survival after resection of pancreatic adenocarcinoma: Results from a single institution over three decades. Ann. Surg. Oncol. 2012, 19, 169. [CrossRef]

15. Bradley, A.; Van Der Meer, R. Upfront Surgery versus Neoadjuvant Therapy for Resectable Pancreatic Cancer: Systematic Review and Bayesian Network Meta-analysis. Sci. Rep. 2019, 9, 4354. [CrossRef]

16. Bilimoria, K.Y.; Bentrem, D.J.; Ko, C.Y.; Tomlinson, J.S.; Stewart, A.K.; Winchester, D.P.; Talamonti, M.S. Multimodality therapy for pancreatic cancer in the U.S.: Utilization, outcomes, and the effect of hospital volume. Cancer 2007, 110, 1227-1234. [CrossRef]

17. Haeno, H.; Gonen, M.; Davis, M.B.; Herman, J.M.; Iacobuzio-Donahue, C.A.; Michor, F. Computational modeling of pancreatic cancer reveals kinetics of metastasis suggesting optimum treatment strategies. Cell 2012, 148, 362-375. [CrossRef]

18. Assifi, M.M.; Lu, X.; Eibl, G.; Reber, H.A.; Li, G.; Hines, O.J. Neoadjuvant therapy in pancreatic adenocarcinoma: A meta-analysis of phase II trials. Surgery 2011, 150, 466-473. [CrossRef]

19. Gillen, S.; Schuster, T.; Meyer Zum Büschenfelde, C.; Friess, H.; Kleeff, J. Preoperative/neoadjuvant therapy in pancreatic cancer: A systematic review and meta-analysis of response and resection percentages. PLoS Med. 2010, 7, e1000267. [CrossRef]

20. Tajima, H.; Ohta, T.; Okazaki, M.; Yamaguchi, T.; Ohbatake, Y.; Okamoto, K.; Nakanuma, S.; Kinoshita, J.; Makino, I.; Nakamura, K.; et al. Neoadjuvant chemotherapy with gemcitabine-Based regimens improves the prognosis of node positive resectable pancreatic head cancer. Mol. Clin. Oncol. 2019, 11, 157-166. [CrossRef]

21. Xu, C.P.; Xue, X.J.; Liang, N.; Xu, D.G.; Liu, F.J.; Yu, X.S.; Zhang, J.D. Effect of chemoradiotherapy and neoadjuvant chemoradiotherapy in resectable pancreatic cancer: A systematic review and meta-analysis. J. Cancer Res. Clin. Oncol. 2014, 140, 549-559. [CrossRef] [PubMed] 
22. Andriulli, A.; Festa, V.; Botteri, E.; Valvano, M.R.; Koch, M.; Bassi, C.; Maisonneuve, P.; Sebastiano, P.D. Neoadjuvant/preoperative gemcitabine for patients with localized pancreatic cancer: A meta-analaysis of prospective studies. Ann. Surg. Oncol. 2012, 19, 1644-1662. [CrossRef] [PubMed]

23. De Gus, S.W.; Evans, D.B.; Bliss, L.A.; Eskander, M.F.; Smith, J.K.; Wolff, R.A.; Miksad, R.A. Weinstein MC8, Tseng JF Neoadjuvant therapy versus upfront surgical strategies in resectable pancreatic cancer: A markov decision analysis. Eur. J. Surg. 2016, 42, 1552-1560. [CrossRef]

24. Motoi, F.; Kosuge, T.; Ueno, H.; Yamaue, H.; Satoi, S.; Sho, M.; Honda, G.; Matsumoto, I.; Wada, K.; Furuse, J.; et al. Randomized phase II/III trial of neoadjuvant chemotherapy with gemcitabine and S-1 versus upfront surgery for resectable pancreatic cancer (Prep-02/JSAP05). Jpn. J. Clin. Oncol. 2019, 49, 190-194. [CrossRef] [PubMed]

25. Janssen, Q.P.; Buettner, S.; Suker, M.; Beumer, B.R.; Addeo, P.; Bachellier, P.; Bahary, N.; Bekaii-Saab, T.; Bali, M.A.; Besselink, M.G.; et al. Neoadjuvant FOLFIRINOX in patients with borderline resectable pancreatic cancer: A systematic review and patient-level meta-analysis. J. Natl. Cancer Inst. 2019, 111, 782-794. [CrossRef] [PubMed]

26. Conroy, T.; Desseigne, F.; Ychou, M.; Bouché, O.; Guimbaud, R.; Bécouarn, Y.; Adenis, A.; Raoul, J.-L.; Gourgou-Bourgade, S.; de la Fouchardière, C.; et al. FOLFIRINOX versus gemcitabine for metastatic pancreatic cancer. N. Engl. J. Med. 2011, 364, 1817-1825. [CrossRef]

27. Michelakos, T.; Pergolini, I.; Castillo, C.F.; Honselmann, K.C.; Cai, L.; Deshpande, V.; Wo, J.Y.; Ryan, D.P.; Allen, J.N.; Blaszkowsky, L.S.; et al. Predictors of Resectability and Survival in Patients with Borderline and Locally Advanced Pancreatic Cancer who Underwent Neoadjuvant Treatment with FOLFIRINOX. Ann. Surg. 2019, 269, 733-740. [CrossRef]

28. Tienhoven, G.V.; Versteijne, E.; Suker, M.; Groothuis, K.B.C.; Busch, O.R.; Bonsing, B.A.; de Hingh, I.H.J.T.; Festen, S.; Patijn, G.A.; Vos-Geelen, J.D.; et al. Preoperative chemoradiotherapy versus immediate surgery for resectable and borderline resectable pancreatic cancer (PREOPANC-1): A randomized, controlled, multicenter phase III trial. J. Clin. Oncol. 2018, 36. [CrossRef]

29. Kurahara, H.; Maemura, K.; Mataki, Y.; Sakoda, M.; Iino, S.; Kawasaki, Y.; Arigami, T.; Mori, S.; Kijima, Y.; Ueno, S.; et al. A Therapeutic strategy for resectable pancreatic cancer based on risk factors of early recurrence. Pancreas 2018, 47, 753-758. [CrossRef]

30. Kanda, M.; Fujii, T.; Kodera, Y.; Nagai, S.; Takeda, S.; Nakao, A. Nutritional predictors of postoperative outcome in pancreatic cancer. Br. J. Surg. 2011, 98, 268-274. [CrossRef]

31. Griffin, O.M.; Duggan, S.N.; Ryan, R.; McDermott, R.; Geoghegan, J.; Conlon, K.C. Characterising the impact of body composition change during neoadjuvant chemotherapy for pancreatic cancer. Pancreatology 2019, 19, 850-857. [CrossRef] [PubMed]

32. Celgene Provides Update on ABRAXANEßCombination Therapy in the Treatment of Metastatic Triple-Negative Breast Cancer and Pancreatic Cancer. Available online: https://ir.celgene.com/pressreleases/press-release-details/2019/Celgene-Provides-Update-on-ABRAXANE-Combination-Therapy-inthe-Treatment-of-Metastatic-Triple-Negative-Breast-Cancer-and-Pancreatic-Cancer/default.aspx (accessed on 21 March 2019).

33. Sohal, D.; McDonough, S.; Ahmad, S.A.; Gandhi, N.; Shaalan Beg, M.; Wang-Gillam, A.; Wade, J.L.; Guthrie, K.A.; Lowy, A.M.; Agop Philip, P.; et al. SWOG S1505: Initial findings on eligibility and neoadjuvant chemotherapy experience with mfolfirinox versus gemcitabine/nab-paclitaxel for resectable pancreatic adenocarcinoma. J. Clin. Oncol. 2019, 37, 414. [CrossRef]

34. Cancer Research UK. Available online: https://www.cancerresearchuk.org/about-cancer/find-a-clinical-trial/ a-study-looking-at-chemotherapy-or-chemoradiotherapy-before-surgery-for-pancreatic-cancer-espac-5f? _ga=2.4165552.1082708421.1573202936-1348630287.1565085295 (accessed on 7 December 2018).

35. Kunzmann, V.; Hartlapp, I.; Scheurlen, M.; Einsele, H.; Mueller, J.; KennUlrich Steger, W.; Germer, C.T. Sequential neoadjuvant chemotherapy with nab-paclitaxel plus gemcitabine and FOLFIRINOX in locally advanced pancreatic cancer (LAPC): A PILOT study. J. Clin. Oncol. 2013, 31, e15193.

36. Sueyoshi, H.; Ioka, T.; Tamura, T.; Takada, R.; Fukutake, N.; Ohkawa, R.A.K.; Takahashi, H.; Teshima, T.; Katayama, K. Phase I study of chemoradiation therapy (nab-paclitaxel/Gemcitabine) in 15 patients with unresectable locally advanced pancreatic cancer (UR-LAPC). J. Clin. Oncol. 2015, 33, 475. [CrossRef] 
37. Reni, M.; Balzano, G.; Zanon, S.; Passoni, P.; Nicoletti, R.; Arcidiacono, P.G.; Pepe, G.; Doglioni, C.; Fugazza, C.; Ceraulo, D.; et al. Phase 1B trial of Nab-paclitaxel plus gemcitabine, capecitabine, and cisplatin (PAXG regimen) in patients with unresectable or borderline resectable pancreatic adenocarcinoma. Br. J. Cancer 2016, 115, 290-296. [CrossRef]

38. Reni, M.; Zanon, S.; Balzano, G.; Nobile, S.; Pircher, C.C.; Chiaravalli, M.; Passoni, P.; Arcidiacono, P.G.; Nicoletti, R.; Crippa, S.; et al. Selecting patients for resection after primary chemotherapy for non-metastatic pancreatic adenocarcinoma. Ann. Oncol. 2017, 28, 2786-2792. [CrossRef]

39. Hammel, P.; Lacy, J.; Portales, F.; Sobrero, A.F.; Pazo Cid, R.A.; Mozo, J.L.M.; Terrebonne, E.; Dowden, S.D.; Li, J.S.; Ong, T.J.; et al. Phase II LAPACT trial of nab-paclitaxel (nab-P) plus gemcitabine (G) for patients with locally advanced pancreatic cancer (LAPC). J. Clin. Oncol. 2018, 36, 204. [CrossRef]

40. Reni, M.; Zanon, S.; Balzano, G.; Passoni, P.; Pircher, C.; Chiaravalli, M.; Fugazza, C.; Ceraulo, D.; Nicoletti, R.; Arcidiacono, P.G.; et al. A randomised phase 2 trial of nab-paclitaxel plus gemcitabine with or without capecitabine and cisplatin in locally advanced or borderline resectable pancreatic adenocarcinoma. Eur. J. Cancer 2018, 102, 95-102. [CrossRef]

41. Khushman, M.; Dempsey, N.; Maldonado, J.C.; Loaiza-Bonilla, A.; Velez, M.; Carcas, L.; Dammrich, D.; Hurtado-Cordovi, J.; Parajuli, R.; Pollack, T.; et al. Full dose neoadjuvant FOLFIRINOX is associated with prolonged survival in patients with locally advanced pancreatic adenocarcinoma. Pancreatology 2015, 15, 667-673. [CrossRef]

42. Nitsche, U.; Wenzel, P.; Siveke, J.T.; Braren, R.; Holzapfel, K.; Schlitter, A.M.; Stöß, C.; Kong, B.; Esposito, I.; Erkan, M.; et al. Resectability after first-line FOLFIRINOX in initially unresectable locally advanced pancreatic cancer: A single-center experience. Ann. Surg. Oncol. 2015, 22, 1212-1220. [CrossRef]

43. Kato, H.; Isaji, S.; Azumi, Y.; Kishiwada, M.; Hamada, T.; Mizuno, S.; Usui, M.; Sakurai, H.; Tabata, M. Development of nonalcoholic fatty liver disease (NAFLD) and nonalcoholic steatohepatitis (NASH) after pancreaticoduodenectomy: Proposal of a postoperative NAFLD scoring system. J. Hepatobil. Pancreat. Sci. 2010, 17, 296-304. [CrossRef] [PubMed]

44. Pfeiffer, P.; Ladekarl, M.; Mortensen, M.B.; Fromm, A.-L.; Bjerregaard, J.K. Chemotherapy for patients with non-resectable pancreatic cancer with additional chemo-radiotherapy for patients with potentially resectable tumours: Final results. Ann. Oncol. 2016, 27, 680. [CrossRef]

45. Suker, M.; Beumer, B.R.; Sadot, E.; Marthey, L.; Faris, J.E.; Mellon, E.A.; El-Rayes, B.F.; Wang-Gillam, A.; Lacy, J.; Hosein, P.J.; et al. FOLFIRINOX for locally advanced pancreatic cancer: A systematic review and patient-level metaanalysis. Lancet Oncol. 2016, 17, 801-810. [CrossRef]

46. Lloyd, S.; Chang, B.W. A comparison of three treatment strategies for locally advanced and borderline resectable pancreatic cancer. J. Gastrointest. Oncol. 2013, 4, 123-130.

47. Casadei, R.; Di Marco, M.; Ricci, C.; Santini, D.; Serra, C.; Calculli, L.; D’Ambra, M.; Guido, A.; Morselli-Labate, A.M.; Minni, F. Neoadjuvant chemoradiotherapy and surgery versus surgery alone in resectable pancreatic cancer: A single-center prospective, randomized, controlled trial which failed to achieve accrual targets. J. Gastrointest. Surg. 2015, 19, 1802-1812. [CrossRef]

48. Fujii, T.; Yamada, S.; Murotani, K.; Kanda, M.; Sugimoto, H.; Nakao, A.; Kodera, Y. Inverse probability of treatment weighting analysis of upfront surgery versus neoadjuvant chemoradiotherapy followed by surgery for pancreatic adenocarcinoma with arterial abutment. Medicine 2015, 94, e1647. [CrossRef]

49. Fujii, T.; Satoi, S.; Yamada, S.; Murotani, K.; Yanagimoto, H.; Takami, H.; Yamamoto, T.; Kanda, M.; Yamaki, S.; Hirooka, S.; et al. Clinical benefits of neoadjuvant chemoradiotherapy for adenocarcinoma of the pancreatic head: An observational study using inverse probability of treatment weighting. J. Gastroenterol. 2017, 52, 81-93. [CrossRef]

50. Satoi, S.; Yanagimoto, H.; Yamamoto, T.; Ohe, C.; Miyasaka, C.; Uemura, Y.; Hirooka, S.; Yamaki, S.; Ryota, H.; Michiura, T.; et al. Clinical outcomes of pancreatic ductal adenocarcinoma resection following neoadjuvant chemoradiation therapy vs. chemotherapy. Surg. Today 2017, 47, 84-91. [CrossRef]

51. Murakami, Y.; Uemura, K.; Sudo, T.; Hashimoto, Y.; Kondo, N.; Nakagawa, N.; Takahashi, S.; Sueda, T. Survival impact of neoadjuvant gemcitabine plus S-1 chemotherapy for patients with borderline resectable pancreatic carcinoma with arterial contact. Cancer Chemother. Pharmacol. 2017, 79, 37-47. [CrossRef] 
52. Neoptolemos, J.P.; Palmer, D.H.; Ghaneh, P.; Psarelli, E.E.; Valle, J.W.; Halloran, C.M.; Faluyi, O.; O’Reilly, D.A.; Cunningham, D.; Wadsley, J.; et al. Comparison of adjuvant gemcitabine and capecitabine with gemcitabine monotherapy in patients with resected pancreatic cancer (ESPAC-4): A multicentre, open-label, randomised, phase 3 trial. Lancet 2017, 389, 1011-1024. [CrossRef]

53. Ueno, H.; Kosuge, T.; Matsuyama, Y.; Yamamoto, J.; Nakao, A.; Egawa, S.; Doi, R.; Monden, M.; Hatori, T.; Tanaka, M.; et al. A randomised phase III trial comparing gemcitabine with surgery-only in patients with resected pancreatic cancer: Japanese Study Group of Adjuvant Therapy for Pancreatic Cancer. Br. J. Cancer 2009, 101, 908-915. [CrossRef] [PubMed]

54. Valle, J.W.; Palmer, D.; Jackson, R.; Cox, T.; Neoptolemos, J.P.; Ghaneh, P.; Rawcliffe, C.L.; Bassi, C.; Stocken, D.D.; Cunningham, D. Optimal duration and timing of adjuvant chemotherapy after definitive surgery for ductal adenocarcinoma of the pancreas: Ongoing lessons from the ESPAC-3 study. J. Clin. Oncol. 2014, 32, 504-512. [CrossRef] [PubMed]

55. Uesaka, K.; Boku, N.; Fukutomi, A.; Okamura, Y.; Konishi, M.; Matsumoto, I.; Kaneoka, Y.; Shimizu, Y.; Nakamori, S.; Sakamoto, H.; et al. Adjuvant chemotherapy of S-1 versus gemcitabine for resected pancreatic cancer: A phase 3, open-label, randomised, non-inferiority trial (JASPAC 01). Lancet 2016, 388, $248-257$. [CrossRef]

56. Conroy, T.; Hammel, P.; Hebbar, M.; Ben Abdelghani, M.; Wei, A.C.; Raoul, J.L.; Choné, L.; Francois, E.; Artru, P.; Biagi, J.J.; et al. FOLFIRINOX or Gemcitabine as Adjuvant Therapy for Pancreatic Cancer. N. Engl. J. Med. 2018, 379, 2395-2406. [CrossRef] [PubMed]

57. Tempero, M.A.; Reni, M.; Riess, H.; Pelzer, U.; O’Reilly, E.M.; Winter, J.M.; Oh, D.-Y.; Li, C.-Y.; Tortora, G.; Chang, H.M.; et al. APACT: Phase III, multicenter, international, open-label, randomized trial of adjuvant nab-paclitaxel plus gemcitabine (nab-P/G) vs gemcitabine $(\mathrm{G})$ for surgically resected pancreatic adenocarcinoma. J. Clin. Oncol. 2019, 37, 4000. [CrossRef]

58. Altman, A.M.; Wirth, K.; Marmor, S.; Lou, E.; Chang, K.; Hui, J.Y.C.; Tuttle, T.M.; Jensen, E.H.; Denbo, J.W. Completion of Adjuvant Chemotherapy After Upfront Surgical Resection for Pancreatic Cancer Is Uncommon Yet Associated with Improved Survival. Ann. Surg. Oncol. 2019, 26, 4108-4116. [CrossRef] [PubMed]

59. Akahori, T.; Sho, M.; Tanaka, T.; Kinoshita, S.; Nagai, M.; Nishiwada, S.; Nishiofuku, H.; Ohbayashi, C.; Kichikawa, K.; Nakajima, Y. Factors associated with failure to complete adjuvant chemotherapy in pancreatic cancer. Am. J. Surg. 2016, 211, 787-792. [CrossRef]

60. Aloia, T.E.; Lee, J.E.; Vauthey, J.N.; Abdalla, E.K.; Wolff, R.A.; Varadhachary, G.R.; Abbruzzese, J.L.; Crane, C.H.; Evans DBPisters, P.W. Delayed recovery after pancreaticduodenectomy: A major factor impairing the delivery of adjuvant therapy? J. Am. Coll. Surg. 2007, 204, 347-355. [CrossRef]

61. Merkow, R.P.; Bilimoria, K.Y.; Tomlinson, J.S.; Paruch, J.L.; Fleming, J.B.; Talamonti, M.S.; Ko, C.Y.; Bentrem, D.J. Postoperative complications reduce adjuvant chemotherapy use in resectable pancreatic cancer. Ann. Surg. 2014, 260, 372-377. [CrossRef]

62. Wu, W.; He, J.; Cameron, J.L.; Makary, M.; Soares, K.; Ahuja, N.; Rezaee, N.; Herman, J.; Zheng, L.; Laheru, D.; et al. The impact of postoperative complications on the administration of adjuvant therapy following pancreaticoduodenectomy for adenocarcinoma. Ann. Surg. Oncol. 2014, 21, 2873-2881. [CrossRef]

63. Labori, K.J.; Katz, M.H.; Tzeng, C.W.; Bjørnbeth, B.A.; Cvancarova, M.; Edwin, B.; Kure, E.H.; Eide, T.J.; Dueland, S.; Buanes, T.; et al. Impact of early disease progression and surgical complications on adjuvant chemotherapy completion rates and survival in patients undergoing the surgery first approach for resectable pancreatic ductal adenocarcinoma-A population-based cohort study. Acta Oncol. 2016, 55, $265-277$. [CrossRef] [PubMed]

64. Schwarz, L.; Bruno, M.; Parker, N.H.; Prakash, L.; Mise, Y.; Lee, J.E.; Vauthey, J.N.; Aloia, T.A.; Conrad, C.; Fleming, J.B.; et al. Active Surveillance for Adverse Events Within 90 Days: The Standard for Reporting Surgical Outcomes After Pancreatectomy. Ann. Surg. Oncol. 2015, 22, 3522-3529. [CrossRef] [PubMed]

65. Waraya, M.; Yamashita, K.; Katagiri, H.; Ishii, K.; Takahashi, Y.; Furuta, K.; Watanabe, M. Preoperative serum CA19-9 and dissected peripancreatic tissue margin as determiners of long-term survival in pancreatic cancer. Ann. Surg. Oncol. 2009, 16, 1231-1240. [CrossRef] [PubMed]

66. Ueda, M.; Endo, I.; Nakashima, M.; Minami, Y.; Takeda, K.; Matsuo, K.; Nagano, Y.; Tanaka, K.; Ichikawa, Y.; Togo, S.; et al. Prognostic factors after resection of pancreatic cancer. World. J. Surg. 2009, 33, 104-110. [CrossRef] 
67. Esposito, I.; Kleeff, J.; Bergmann, F.; Reiser, C.; Herpel, E.; Friess, H.; Schirmacher, P.; Büchler, M.W. Most pancreatic cancer resections are R1 resections. Ann. Surg. Oncol. 2008, 15, 1651-1660. [CrossRef]

68. Eguchi, H.; Yamada, D.; Iwagami, Y.; Gotoh, K.; Kawamoto, K.; Wada, H.; Asaoka, T.; Noda, T.; Takeda, Y.; Tanemura, M.; et al. Prolonged neoadjuvant therapy for locally advanced pancreatic cancer. Dig. Surg. 2018, 35, 70-76. [CrossRef]

69. Tzeng, C.W.; Tran Cao, H.S.; Lee, J.E.; Pisters, P.W.; Varadhachary, G.R.; Wolff, R.A.; Abbruzzese, J.L.; Crane, C.H.; Evans, D.B.; Wang, H.; et al. Treatment sequencing for resectable pancreatic cancer: Influence of early metastases and surgical complications on multimodality therapy completion and survival. J. Gastrointest. Surg. 2014, 18, 16-24. [CrossRef]

70. Ettrich, T.J.; Berger, A.W.; Perkhofer, L.; Daum, S.; König, A.; Dickhut, A.; Wittel, U.; Wille, K.; Geissler, M.; Algül, H. Neoadjuvant plus adjuvant or only adjuvant nab-paclitaxel plus gemcitabine for resectable pancreatic cancer-The NEONAX trial (AIO-PAK-0313), a prospective, randomized, controlled, phase II study of the AIO pancreatic cancer group. BMC Cancer 2018, 18, 1298. [CrossRef]

71. MacKenzie, S.H.Z.; McCahill, L.E.; McCahill, L.E.; Sielaff, T.D.; Bahary, N.; Edward, T.; Seng, G.E.; Leach, G.W.; Harmon, J.; Demeure, M.J.; et al. A pilot phase II multicenter study of nab-paclitaxel (Nab-P) and gemcitabine (G) as preoperative therapy for potentially resectable pancreatic cancer (PC). J. Clin. Oncol. 2013, 2013, 31.

72. Von Hoff, D.D.; Ramanathan, R.K.; Borad, M.J.; Laheru, D.A.; Smith, L.S.; Wood, T.E.; Korn, R.L.; Desai, N.; Trieu, V.; Iglesias, J.L.; et al. Gemcitabine plus nab-paclitaxel is an active regimen in patients with advanced pancreatic cancer: A phase I/II trial. J. Clin. Oncol. 2011, 29, 4548-4554. [CrossRef]

73. Heinrich, S.; Pestalozzi, B.; Lesurtel, M.; Berrevoet, F.; Laurent, S.; Delpero, J.R.; Raoul, J.L.; Bachellier, P.; Dufour, P.; Moehler, M.; et al. Adjuvant gemcitabine versus NEOadjuvant gemcitabine/oxaliplatin plus adjuvant gemcitabine in resectable pancreatic cancer: A randomized multicenter phase III study (NEOPAC study). BMC Cancer 2011, 11, 346. [CrossRef] [PubMed]

74. Hozaeel, W.; Pauligk, C.; Homann, N.; Luley, K.; Kraus, T.W.; Bechstein, T.J.W.O.; Grimm, K.; Heise, B.; Schmiegel, W.; Pink, D.; et al. Randomized multicenter phase II/III study with adjuvant gemcitabine versus neoadjuvant/adjuvant FOLFIRINOX in resectable pancreatic cancer: The NEPAFOX trial. J. Clin. Oncol. 2017. [CrossRef]

75. Labori, K.J.; Lassen, K.; Hoem, D.; Grønbech, J.E.; Søreide, J.A.; Mortensen, K.; Smaaland, R.; Sorbye, H.; Verbeke, C.; Dueland, S. Neoadjuvant chemotherapy versus surgery first for resectable pancreatic cancer (Norwegian Pancreatic Cancer Trial-1 (NorPACT-1))—study protocol for a national multicentre randomized controlled trial. BMC Surg. 2017, 17, 94. [CrossRef] [PubMed]

76. Schwarz, L.; Vernerey, D.; Bachet, J.-B.; Tuech, J.J.; Portales, F.; Michel, P.; Sa Cunha, A. Resectable pancreatic adenocarcinoma neo-adjuvant FOLF(IRIN)OX-based chemotherapy-A multicenter, noncomparative, randomized, phase II trial (PANACHE01-PRODIGE48 study). BMC Cancer 2018, 18, 762. [CrossRef]

77. Gbolahan, O.B.; Tong, Y.; Sehdev, A.; O'Neil, B.; Shahda, S. Overall survival of patients with recurrent pancreatic cancer treated with systemic therapy: A retrospective study. BMC Cancer 2019, 19, 468. [CrossRef] 